\title{
Pharmacokinetics of rectal compared to intramuscular paracetamol in children undergoing minor surgery
}

\author{
Renuka Kulkarni, Nandini Dave*, Ashish Bartakke*, Abhijeet Nair*, P.P. Kadam*, U.M. Thatte, S.N. Oak^
}

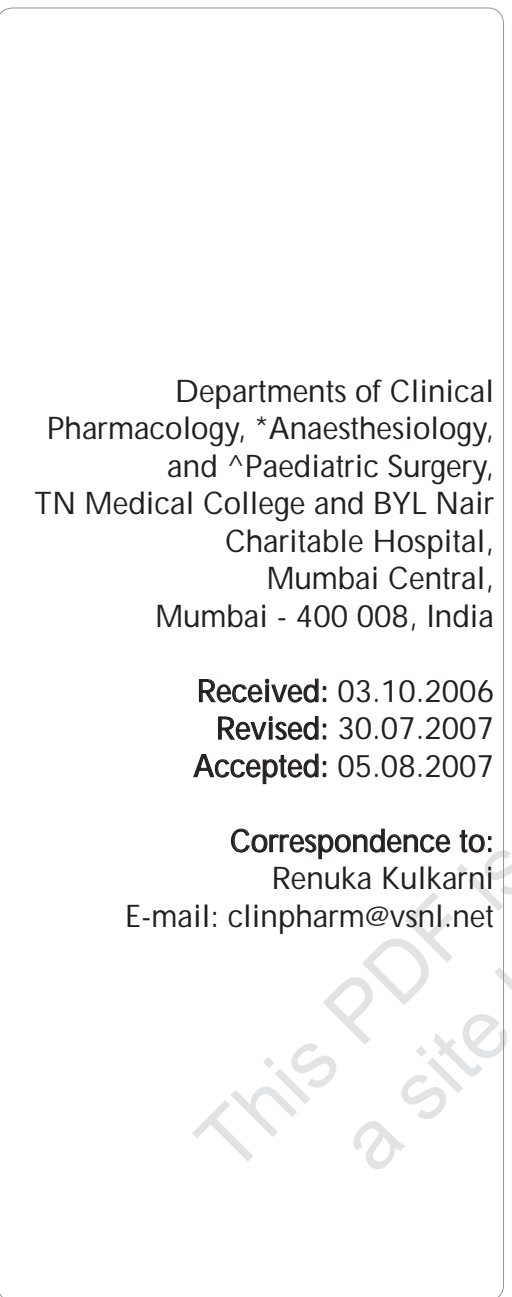

\begin{abstract}
Objectives: Although paracetamol is a widely accepted and safe analgesic, guidelines regarding its definite analgesic dose are lacking. This study was, therefore, undertaken to compare the pharmacokinetics of paracetamol when administered by two routes, viz, intramuscular and rectal, in children undergoing minor surgery.

Design: Randomized, controlled, assessor-blind, comparative clinical trial.

Materials and Methods: Following Institutional Ethics Committee approval and valid consent, children undergoing minor surgery were randomized to receive paracetamol either intramuscularly or rectally. Blood samples were collected at fixed intervals for estimation of drug levels.

Results: Fifty children ( 43 boys, 7 girls; ages 3 to 12 years; weight 10 to $40 \mathrm{~kg}$ ) were enrolled in the study. 26 patients were randomized to receive paracetamol intramuscularly (mean dose $14.8 \pm 0.9 \mathrm{mg} / \mathrm{kg}$ ) and 24 to receive the paracetamol as a rectal suppository (mean dose $29.5 \pm 1.4 \mathrm{mg} / \mathrm{kg}$ ). Complete pharmacokinetic analysis was possible in only 29 patients, as the blood samples of the others were either not received or were inadequate for analysis. The mean maximum plasma concentration $\left(\mathrm{C}_{\max }\right)$ with rectal paracetamol $\left(\mathrm{n}=13\right.$ ) was $6.04 \pm 2.21 \mu \mathrm{g} / \mathrm{ml}$ with a $\mathrm{T}_{\max }$ of $2.5 \pm 0.89 \mathrm{~h}$, while with intramuscular paracetamol $(n=16)$, the $C_{\max }$ was $10.34 \pm 7.09 \mu \mathrm{g} / \mathrm{ml}$ and the $T_{\max } 1.47 \pm 0.64 \mathrm{~h}$. The area under the concentration-time curve ( $A \cup \mathrm{C}_{0-12}$ ) was $42.26 \pm 22.29 \mu \mathrm{g} . \mathrm{h} / \mathrm{ml}$ and 43.60 $\pm 26.45 \mu \mathrm{g} . \mathrm{hr} / \mathrm{ml}$ for rectal and intramuscular paracetamol, respectively. Patients in the intramuscular group needed rescue medication earlier as compared to those in the rectal group $(P<0.05)$.

Conclusion: Although the drug levels achieved with rectal paracetamol were less than that achieved with intramuscular administration, it was higher than the lower limit for analgesic effect (3-5 $\mu \mathrm{g} / \mathrm{ml})$. Patients who received paracetamol intramuscularly needed rescue medication earlier compared to those receiving paracetamol rectally, indicating a more prolonged duration of action with rectally administered paracetamol. Hence, rectal paracetamol can be used as a safe, effective, and more acceptable analgesic alternative in children.
\end{abstract}

KEY W ORDS: Intramuscular route, paracetamol, pharmacokinetics, rectal suppository
Perioperative analgesia, especially in children, is a challenge. The intraoperative use of paracetamol has been suggested as a method to improve postoperative analgesia and reduce opioid requirements following surgery. ${ }^{[1,2]}$ Oral administration of paracetamol is often not possible in a perioperative setting and hence, especially in children, it is administered by the parenteral route. This raises the issue of the hazards associated with injections. Besides, injections are painful and not acceptable to children.

The rectal route has been used for administration of medicines for various reasons; for example, the need to bypass the first-pass metabolism; in unconscious or uncooperative patients or in children, where the oral route is not convenient; to avoid using the parenteral route; to avoid gastric irritation, etc. The extensive vascular supply in the rectum also allows for good absorption. If the medicine is absorbed in the upper part of the rectum it is carried into the portal circulation via the 
superior hemorrhoidal vein, whereas if absorbed from the lower part of the rectum it enters the systemic circulation directly. ${ }^{[3,4]}$ Many medicines are administered in the suppository form, including indomethacin in rheumatoid arthritis and diazepam in febrile convulsions. ${ }^{[1]}$

Several, recent studies have evaluated the analgesic efficacy of rectal paracetamol and, conventionally, a dose of $10-20 \mathrm{mg} / \mathrm{kg}$ is recommended by this route. ${ }^{|5|}$ One of the problems associated with the rectal administration of paracetamol is the erratic absorption, leading to varying clinical responses and, therefore, making it difficult to set clear-cut guidelines for perioperative use, especially in children.

Since rectal paracetamol has only recently been introduced in the Indian market, this study was undertaken to compare the pharmacokinetic profile of paracetamol given by the rectal and intramuscular routes in children undergoing minor surgery.

\section{Materials and Methods}

This was a randomized, controlled, assessor-blind, comparative clinical study that was initiated after obtaining Institutional Ethics Committee approval. Children between the ages of 3 and 12 years, scheduled to undergo minor surgery (i.e., surgeries that lasted only for an hour), who could be categorized into class I (having no systemic illness) of the American Society of Anesthesiologists (ASA) classification, were screened by the trial physicians from the departments of pediatric surgery and anesthesiology. Prior to the screening, written informed consent was taken from their parents or legal guardians and assent from older children (between the ages of 8 and 12 years). Children were excluded if they had received paracetamol $24 \mathrm{~h}$ prior to surgery, had rectal dysfunction that might have impaired their ability to retain the suppository or influenced the absorption of paracetamol, had a history of intolerance to paracetamol, or if the parent or guardian refused consent.

The allocation sequence was generated using computergenerated numbers at the department of Clinical Pharmacology and was concealed in sealed envelopes, each envelope containing the randomization code of one subject. The envelopes were handed over to, and opened by, the trial physicians of the departments of anesthesiology and pediatric surgery on the day of the surgery of a recruited subject. Based on the allocation sequence, recruited children were randomized to one of the two study groups by the trial physicians. Group I was administered a single intramuscular (IM) injection of paracetamol (J-Mol, Ess Jee Pharmaceuticals; $150 \mathrm{mg} / \mathrm{ml}$ ) in a dose of $15 \mathrm{mg} / \mathrm{kg}$. Group II received paracetamol as a rectal suppository (Anamol, Elder Pharmaceuticals; dosage strength 80, 170, and $250 \mathrm{mg}$ ) in a dose of $30 \mathrm{mg} / \mathrm{kg}$. Combinations of the three commercially available doses $(80,170$, and $250 \mathrm{mg})$ were used to deliver an amount of drug as close as possible to the desired dose. Both groups received the paracetamol at the time of incision.

During the surgery, general anesthesia was administered as per standard procedure. All patients received an intravenous opioid (pentazocine $0.5 \mathrm{mg} / \mathrm{kg}$ ) as premedication $5 \mathrm{~min}$ before induction. An intravenous cannula was inserted for withdrawal of blood for the estimation of drug levels. After administration of paracetamol, given as per the randomization code, heparinized venous blood (maximum of $2 \mathrm{ml}$ per collection) was collected at $0.5,1,1.5,2,3,4,6$, and $12 \mathrm{~h}$ following drug administration (a total of 9 blood samples per patient, including the one at baseline, prior to administration of paracetamol).

Plasma was separated and refrigerated at $-20^{\circ} \mathrm{C}$ till the assay was performed by a laboratory technician blinded to the treatment details of the patients. Paracetamol levels were estimated using the high-performance liquid chromatography (HPLC) method of Qu et al. ${ }^{[6]}$ and Kushida et al. ${ }^{[7]}$ Pharmacokinetic parameters calculated from the time-concentration curves plotted for each individual included maximum plasma concentration $\left(\mathrm{C}_{\max }\right)$, time to maximal plasma concentration $\left(\mathrm{T}_{\text {max }}\right)$, and area under the time-concentration curve (AUC), which was calculated using the Trapezoidal rule.

As it was difficult to assess pain in children using one standard scale due to the wide variation in the ages of the children recruited in the study, it was decided to rely on clinical criteria; in the younger age-group (3-5 years), the patient's irritability, refusal to obey verbal suggestions, not attending to visual clues, grimaces, and resentment to touch were taken as indicators of pain to assess the necessity for rescue medication, whereas in older children rescue medication was given on verbal request for pain relief. Parents' requests were also given due consideration. These parameters were assessed at hourly intervals by a physician blinded to the treatment given to the subject. The time to administration of the rescue analgesic was also recorded (rescue medication being intravenous pentazocine, $0.5 \mathrm{mg} / \mathrm{kg}$ ).

\section{Paracetamol assay}

Paracetamol concentration was determined by high performance liquid chromatography (HPLC). ${ }^{[6,7]}$ After thawing, $250 \mu \mathrm{l}$ of plasma was mixed with $500 \mu \mathrm{l}$ of $0.6 \mathrm{M}$ hydrochloric acid, saturated with ammonium sulphate and vortexed for 20 s. Subsequently, $300 \mu \mathrm{l}$ acetonitrile was added and the whole aliquot centrifuged at $2700 \mathrm{~g}$ for $10 \mathrm{~min}$. The supernatant was separated and $20 \mu \mathrm{l}$ was injected into the HPLC system.

The Thermoquest (TSP) HPLC system integrated with SCM1000 degasser, P4000 pump, 7725Rheodyne injector, and UV3000 detector supported by ChromQuest 3.0 software with a high purity advanced C18 $(4.6 \times 250 \mathrm{~mm}, 5 \mu \mathrm{m})$ column was used. The chromatographic conditions were as follows: wavelength $254 \mathrm{~nm}$, mobile phase consisted of acetonitrile: $100 \mathrm{mM}$ potassium di-hydrogen phosphate buffer of $\mathrm{pH} 4.0$ $(9.75: 90.25 \mathrm{v} / \mathrm{v})$. Salicylic acid (Sigma grade) was taken as the internal standard. The standard curves for paracetamol were linear in the range 1-50 $\mu \mathrm{g} / \mathrm{ml}$. Intra and inter-day precision of the method was estimated by repeated analysis of plasma samples containing known concentrations of the pure standard. The coefficient of variation was $1.01 \%$. The method was specific, no significant interfering peaks were observed. Analyte recovery from the plasma sample was $94.24 \%$.

\section{Statistical considerations}

The randomization sequence was generated using the EpiStat software. Data analysis was done using GraphPad software with Student's t-test to compare the pharmacokinetic variables among the two groups and the chi-square test to compare the number of patients needing rescue medication at the various time points. 


\section{Results}

Seventy-two children admitted for minor surgery were identified; of these, 17 did not meet the eligibility criteria and parents of 5 children refused consent for participation in the study. Hence, 50 children ( 43 boys and 7 girls) were enrolled in the study. The age of the patients ranged from 3 to 12 years and the body weight ranged from 10 to $40 \mathrm{~kg}$. Twenty-six patients were randomized to receive paracetamol intramuscularly (15 $\mathrm{mg} / \mathrm{kg}$ ) and 24 patients to receive the rectal suppository (30 $\mathrm{mg} / \mathrm{kg}$ ). The demographic data summarized in Table 1 indicates that the two groups were comparable. This study, including the pharmacokinetic analysis, was carried out from August 2004 to November 2005.

Paracetamol estimation could not be performed at all time points in 21 children as either the sample was inadequate or had hemolysed. Hence, we had a total of 29 evaluable patients for pharmacokinetic analysis of which group I (who received IM paracetamol) had 16 evaluable patients and group II (those who received rectal paracetamol) had 13 evaluable participants. The study flowchart giving details of screening, recruitment allocation to study treatments, and analysis is given in Figure 1.

The mean maximum plasma concentration $\left(\mathrm{C}_{\max }\right)$ of paracetamol was significantly higher when given intramuscularly $(10.34 \pm 7.086 \mu \mathrm{g} / \mathrm{ml})$ as compared to the $\mathrm{C}_{\max }$ when given rectally $(6.04 \pm 2.21 \mu \mathrm{g} / \mathrm{ml})(\mathrm{P}<0.05)$. Similarly, the time to achieve peak levels $\left(\mathrm{T}_{\max }\right)$ was significantly shorter with IM paracetamol $(1.47 \pm 0.65 \mathrm{~h})$ than with rectal paracetamol (2.5 $\pm 0.89 \mathrm{~h})(\mathrm{P}<0.05)$.

The half-life $\left(\mathrm{t}_{1 / 2}\right)$ of paracetamol when given rectally was $2.24 \pm 0.57 \mathrm{~h}$ and $2.74 \pm 1.40 \mathrm{~h}$ when given intramuscularly.

There was no significant difference in the total concentrations of paracetamol achieved in the body over $12 \mathrm{~h}$ when given by

\section{Table 1}

Demographic data of patients from groups I and II

\begin{tabular}{lcc}
\hline & $\begin{array}{c}\text { Group I (IM PCM) } \\
(\boldsymbol{n}=\mathbf{2 6})\end{array}$ & $\begin{array}{c}\text { Group II (Rectal PCM) } \\
(\boldsymbol{n}=\mathbf{2 4})\end{array}$ \\
\hline Age (years) & $8.17 \pm 2.98$ & $7.94 \pm 2.36$ \\
Weight $(\mathrm{kg})$ & $20.35 \pm 7.05$ & $20.33 \pm 7.10$ \\
Gender & 22 boys: 4 girls & 21 boys: 3 girls \\
\hline
\end{tabular}

Figure 1: Study flowchart

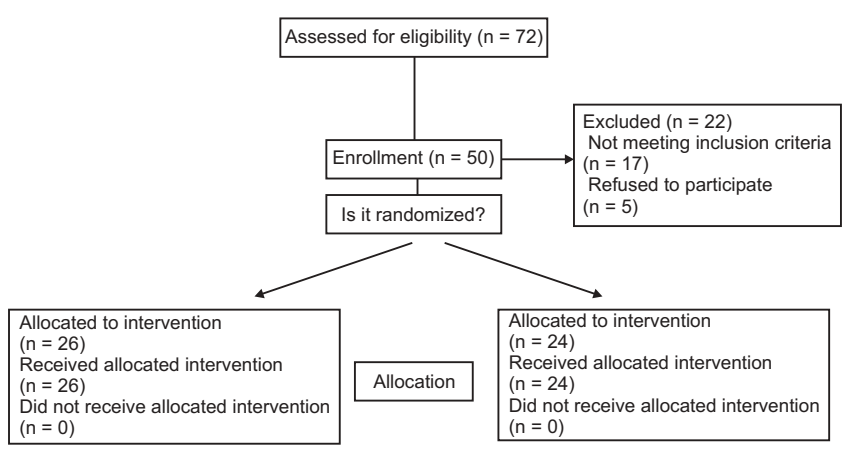

either route; the area under the time-concentration curve at 12 $\mathrm{h}\left(\mathrm{AUC}_{0-12}\right)$ for rectal paracetamol was $42.26 \pm 22.29 \mu \mathrm{g} . \mathrm{h} / \mathrm{ml}$ and that for intramuscular paracetamol was $43.604 \pm 26.45$ $\mu \mathrm{g} . \mathrm{h} / \mathrm{ml}$, respectively [Table 2].

The patients were also assessed at periodic intervals after surgery for the presence of pain and the need for the rescue analgesic (intravenous pentazocine). It was observed that no patient who had received paracetamol as a rectal suppository needed rescue medication for upto $6 \mathrm{~h}$ postoperatively, whereas 6 patients in the intramuscular paracetamol group demanded rescue analgesic before this time point $(\mathrm{P}<0.05)$. Patients who had received intramuscular paracetamol needed rescue medication as early as $4 \mathrm{~h}$ post surgery. The results are presented in Figure 2.

There were no adverse events recorded during the entire study period.

\section{Discussion}

Our study documents the comparative pharmacokinetics of rectal and intramuscular paracetamol. Although the $\mathrm{C}_{\max }$ and $\mathrm{T}_{\max }$ with rectal paracetamol were significantly lower than with the IM route, the AUCs were comparable, and the need for rescue medication was felt later with the rectal route than after IM administration.

The rectal route of drug administration is a practical, alternative route in patients who are unconscious or uncooperative or in cases of nausea and vomiting, convulsions or prior to surgery. This route has been used for the administration

\section{Table 2}

Pharmacokinetic parameters of paracetamol when given in a single dose by the intramuscular and rectal routes

\begin{tabular}{lcc}
\hline & $\begin{array}{c}\text { Group I (IM PCM) } \\
(\boldsymbol{n}=\mathbf{1 6})\end{array}$ & $\begin{array}{c}\text { Group II (Rectal PCM) } \\
(\boldsymbol{n}=\mathbf{1 3})\end{array}$ \\
\hline $\mathrm{C}_{\max }(\mu \mathrm{g} / \mathrm{ml})$ & $10.34 \pm 7.086^{*}$ & $6.04 \pm 2.213$ \\
$\mathrm{~T}_{\max }(\mathrm{h})$ & $1.47 \pm 0.645^{*}$ & $2.5 \pm 0.889$ \\
$\mathrm{AUC}_{(0-12)}(\mu \mathrm{g} \cdot \mathrm{h} / \mathrm{ml})$ & $43.604 \pm 26.453$ & $42.26 \pm 22.291$ \\
$\mathrm{AUC}_{(0-x)}(\mu \mathrm{g} \cdot \mathrm{h} / \mathrm{ml})$ & $42.64 \pm 17.53$ & $51.07 \pm 27.42$ \\
$\mathrm{t}_{1 / 2}(\mathrm{~h})$ & $2.24 \pm 0.568$ & $2.74 \pm 1.399$ \\
\hline${ }^{*} P<0.05$ as compared to group II & \\
\hline
\end{tabular}

Figure 2: Number of patients requiring rescue medication in both groups

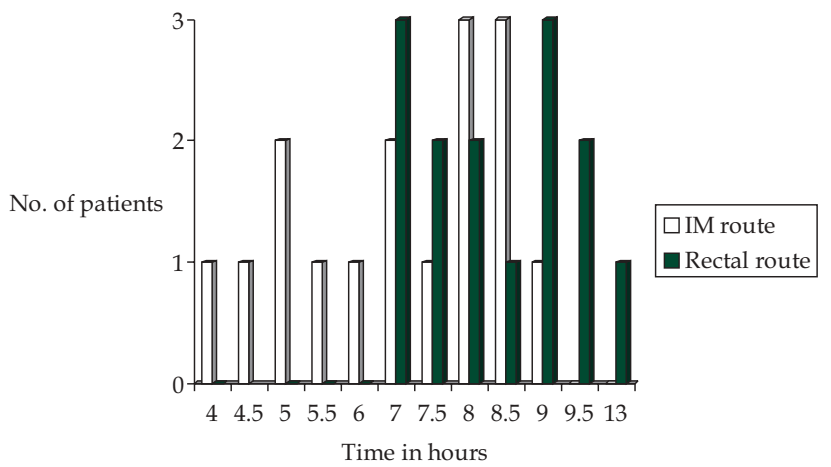


of various drugs, e.g., anticonvulsants, analgesics, theophylline, etc., especially in pediatric patients. ${ }^{[1,5]}$

Paracetamol is widely used to relieve fever and pain in children due to its efficacy and wide safety profile. It is routinely used in the perioperative period to improve analgesia and reduce the need for opioids post surgery. ${ }^{[1]}$ It can be administered either parenterally or rectally to provide perioperative analgesia in children, especially in the period immediately after surgery. The main advantages of the rectal route over the parenteral route is the relative lack of pain during administration and the avoidance of the hazards associated with injections, thus making it the preferred route in children. The rectal formulation of paracetamol has recently been introduced in the Indian market and hence this study was undertaken to compare the pharmacokinetic profile of paracetamol given by the rectal route with that after intramuscular administration and to compare their analgesic effects in the postoperative period in children undergoing minor surgeries.

The recommended dose of paracetamol when given by the parenteral route is $10-15 \mathrm{mg} / \mathrm{kg}^{[5]}$ and hence a dose of 15 $\mathrm{mg} / \mathrm{kg}$ was selected for our study. The dose of paracetamol to be administered rectally was based on literature, wherein higher doses $(15-45 \mathrm{mg} / \mathrm{kg}$ ) have been recommended due to the erratic absorption from the rectum. ${ }^{[8.9]}$ We chose $30 \mathrm{mg} / \mathrm{kg}$ in our study for two reasons; firstly, it was the median dose of the recommended dose range and secondly, we wished to avoid the possible risk of toxicity at higher doses.

Fifty children were enrolled in the study. Pharmacokinetic analysis was possible in only 29 patients because we were not able to collect blood samples at all the specified time points in the other children. It was difficult to collect adequate amounts of blood in the younger children, leading to inadequate plasma for estimation and at times there was also hemolysis of the blood sample, making it unfit for analysis. This highlights the practical difficulties in estimating pharmacokinetics in children.

The pharmacokinetic variables of paracetamol when given by either rectal or intramuscular routes showed that the results were comparable in terms of the area under the serum time-concentration curve (AUC). Although the maximum concentration attained by the rectal route was less than that by the intramuscular route $(6.04 \pm 2.21 \mu \mathrm{g} / \mathrm{ml}$ vs $10.34 \pm$ $7.09 \mu \mathrm{g} / \mathrm{ml} ; \mathrm{P}<0.05)$, it was higher than the lower limit for analgesic effect, i.e., $3-5 \mu \mathrm{g} / \mathrm{ml} .{ }^{[10]}$ Also, the time taken to attain the maximum concentration when given by the rectal route was longer than that by the intramuscular route $(2.5 \pm 0.89 \mathrm{~h}$ vs 1.47 $\pm 0.65 \mathrm{~h} ; \mathrm{P}<0.05)$. However, clinically it was observed that there was a delay in the need for rescue medication in a significantly larger number of patients administered paracetamol rectally as compared to those who received intramuscular paracetamol, indicating a more prolonged duration of action of paracetamol when given rectally.

Various factors may influence the absorption of a drug when given rectally. The rate and extent of dissolution of the rectal suppository is an important factor in determining the degree of absorption and, hence, serum concentration of the drug..$^{[11]}$ The degree of lipophilicity of the vehicle in the suppository, ${ }^{12,13]}$ the suppository dose size (i.e., smaller dose suppositories dissolve more rapidly than larger sizes), ${ }^{[14]}$ presence of multiple suppositories, ${ }^{\mid 15]} \mathrm{pH}$ and temperature within the rectum (influenced by the quantity and consistency of stool in the rectum), and the material that the suppository comes in contact with (stool, bowel mucosa, and other suppositories) are other factors that influence the rate of dissolution, degree of absorption and, hence, the serum concentration achieved by the drug. ${ }^{\mid 16,17]}$

In our study, as there were children aged between 3-12 years with a wide range of body weight, three different suppositories containing different doses of the drug $(80,170$, and $250 \mathrm{mg})$ were combined to deliver the appropriate amount of drug to the children. The presence of multiple suppositories of different sizes could have affected the rate of dissolution of the suppository resulting in the low levels observed in our study. Similarly, as the presence of stool in the rectum can affect drug absorption, giving an enema to the children prior to insertion of the suppository would probably have helped in decreasing the fluctuations in the drug levels.

The placement of the suppository in the rectum is equally important in determining the serum concentrations achieved, due to the variability of the venous drainage from the rectum. If the suppository were placed in the upper part of the rectum, the drug would be absorbed into the portal circulation and would undergo hepatic first-pass metabolism, whereas if it were placed in the lower part of the rectum it would bypass the liver and be directly absorbed into the systemic circulation. ${ }^{[3]}$ Although the placement of the suppository was kept constant during the study, it is difficult in children to exactly differentiate between the upper $1 / 3^{\text {rd }}$ and lower $2 / 3^{\text {rd }}$ of the rectum and hence it is possible that in some of the children, especially in the younger ones, there was a variation in placing the suppository, resulting in differences in absorption, metabolism and hence, drug levels.

Thus, one or more of the above factors could explain the lower serum concentrations of paracetamol observed in our study when given by the rectal route These results are consistent with those obtained in other studies using rectal paracetamol, indicating that the absorption of paracetamol given rectally is erratic and irregular, resulting in lower serum paracetamol concentrations as compared to that with other routes. ${ }^{[8,9,18,19,20-23]}$

However, the total amount of drug available over a given time period was comparable by both routes and, more importantly, none of the children who had received paracetamol rectally needed rescue medication in the first $7 \mathrm{~h}$ postoperatively as compared to six children requiring rescue analgesia in the other group.

Thus, paracetamol when given by the rectal route offered an analgesic effect comparable to that of parenteral paracetamol, without the problems associated with the parenteral route. Hence, rectal paracetamol can be used as a safe, effective, and more acceptable analgesic alternative in children. Because the rectal route leads to slower absorption and a longer time for the drug to achieve peak levels, it may not be recommended as the first choice when rapid relief of analgesia is desired, but it may be a better alternative when a delayed and sustained effect is required, especially in view of its safety and opioidsparing effect.

Although the present study was conducted in children undergoing surgery, the results and the conclusions drawn can 
be extrapolated to nonsurgical situations where paracetamol is used in children.

\section{Acknowledgements}

We thank the Nair Golden Jubilee Research Foundation (NGJRF), TNMC, and BYL Nair Ch. Hospital for financial support to conduct this study. We also acknowledge Elder Pharmaceuticals Limited for the supply of trial medications. We are grateful to Ms. Seema Verma, Mr. Sachin Parab, and Ms. Meghna Subramanium for technical assistance.

\section{References}

1. Satoskar RS, Bhandarkar SD, Ainapure SS. Analgesics-antipyretics and nonsteroidal anti-inflammatory drugs (NSAID). In: Pharmacology and Pharmacotherapeutics. $17^{\text {th }}$ ed. Popular Prakashan: Mumbai; 2001. p. 153-75.

2. Marcia LB. Peri-operative use of high-dose rectal acetaminophen. Pediatr Pharmacother 2001;7:1-7.

3. van Hoogdalem EJ, de Boer AG, Breimer DD. Pharmacokinetics of rectal drug administration, Part II. Clinical applications of peripherally acting drugs, and conclusions. Clin Pharmacokinet 1991;21:110-28.

4. Morselli PL, Franco-Morselli R, Bossi L. Clinical pharmacokinetics in newborns and infants. Age related differences and therapeutic implications. Clin Pharmacokinet 1980;5:485-527.

5. Taketomo CK, Hodding JH, Kraus DM. Pediatric Dosage Handbook. $7^{\text {th }}$ ed. Hudson. Ohio; Lexi-Comp; 2000. p. 26-7.

6. Qu CN, Frawley VL. Theophylline, dyphyline, caffeine, acetaminophen, salicylate, acetylsalicylate, procainamide, $\mathrm{N}$-acetaprocainamide determined in serum with a single liquid chromatographic assay. Clin Chem 1982;28:2157-60.

7. Kushida K, Ishizaki T. Concurrent determination of valproic acid with other anti-epileptic drugs by high performance liquid chromatography. J Chromatogr 1985;338:131-9.

8. Montgomery CJ, McCormack JP, Reichert CC, Marsland CP. Plasma concentrations after high-dose $\left(45 \mathrm{mg}^{\mathrm{kg}}{ }^{-1}\right)$ rectal acetaminophen in children. Can J Anaesth 1995;42:982-6.

9. Anderson B, Kanagasundarum S, Woollard G. Analgesic efficacy of paracetamol in children using tonsillectomy as a pain model. Anaesth Intensive Care 1996;24:669-
73.

10. Dollery C. Therapeutic drugs, Vol. $1 ; 2^{\text {nd }}$ ed. Churchill Livingstone Publications: 1999. p. A19-21.

11. Moolenaar F, Olthof L, Huizinga T. Biopharmaceutics of rectal administration of drugs in man: Absorption rate and bioavailability of paracetamol from rectal aqueous suppositories Pharm Weeklab Scient 1979;1:25-30.

12. Cullen S, Kenny D, Ward OC, Sabra K. Paracetamol suppositories: A comparative study. Arch Dis Child 1989;64:1504-5.

13. Kahela P, Laine $E$, Anttila M. A comparison of the bioavailability of paracetamol from a fatty and a hydrous suppository base and the effect of storage on the absorption in man. Drug Dev Indust Phrma 1987;13:213-24.

14. Birmingham PK, Tobin MJ, Henthorn TK, Fisher DM, Berkelhamer MC, Smith FA, et al. Twenty-four-hour pharmacokinetics of rectal acetaminophen in children: An old drug with new recommendations. Anesthesiology 1997;87:244-52.

15. Narvanen T, Haslas M, Smal J, Marvola M. Olls one Paracetamol suppository of $1000 \mathrm{mg}$ bioequivalent with two suppositories of $500 \mathrm{mg}$. Eur J Drug Metab Pharmacokinet 1998;23:203-6

16. Prescott LF. The absorption of paracetamol. In: Prescott LF, editor. Paracetamol (Acetaminophen) A Critical bibliographic review. Taylor and Francis: London; 1996. p. 36-9.

17. Dange SV, Shah KU, Deshpande AS, Shrotri DS. Bioavailability of acetaminophen after rectal administration. Indian Pediatr 1987;24:331-2.

18. Hansen TG, O'Brien K, Morton NS, Rasmussen SN. Plasma paracetamol concentrations and pharmacokinetics following rectal administration in neonates and young infants. Acta Anaesthesiol Scand 1999;43:855-9.

19. Hahn TW, Henneberg SW, Holm-Knudsen RJ, Eriksen K, Rasmussen SN, Rasmussen M. Pharmacokinetics of rectal paracetamol after repeated dosing in children. Br J Anaesth 2000;85:512-9.

20. Hopkins CS, Underhill S, Booker PD. Pharmacokinetics of paracetamol after cardiac surgery. Arch Dis Child 1990;65:971-6.

21. Anderson BJ, Woolard GA, Holford NH. Pharmacokinetics of rectal paracetamol after major surgery in children. Paediatr Anaesth 1995;5:237-42.

22. Mitchell IM, Jamieson MP, Pollock JC, Logan RW. Paracetamol suppositories after cardiac surgery. Arch Dis Child 1991;66:1004.

23. Stocker ME, Montgomery JE. Serum paracetamol concentrations in adult volunteers following rectal administration. Br J Anaesth 2001;87:638-40. 